\title{
Doença de Bowen Perianal - Diagnóstico e Tratamento: Relato de Caso
}

\author{
Perianal Bowen's Disease - Diagnosis and Treatment: Case Report \\ LUCIANA PAES PEIXOTO NETTO'; HIROTAKAYAMANE'; PAULO CESAR CASTRO JUNIOR ${ }^{1}$; \\ YURI DIAZ YAMANE ${ }^{1}$;ADRIANASANTOS NEVES ${ }^{1}$; FRANCISCO LOPES PAULO ${ }^{1}$ \\ ${ }^{1}$ Serviço de Coloproctologia do Hospital Universitário Pedro Ernesto - Faculdade de Ciências Médicas - \\ Universidade do Estado do Rio de Janeiro
}

\begin{abstract}
PEIXOTO NETTO LP; YAMANE H; CASTRO JR PC; YAMANE YD; NEVES AS; LOPES PAULO F. Doença de Bowen Perianal Diagnóstico e Tratamento: Relato de Caso. Rev bras Coloproct, 2009;29(1): 092-096.

RESUMO: Os autores relatam um caso e objetivam a discussão sobre a Doença de Bowen. Patologia de ocorrência rara, principalmente na região perianal. Trata-se de um carcinoma escamoso in situ com potencial invasor. Apresenta como característica marcante alterações histopatológicas da epiderme que não ultrapassam a membrana basal. É doença de evolução lenta, oligo ou assintomática e de aspecto macroscópico variável. Assim sendo, muitas vezes o diagnóstico é retardado. A confirmação diagnóstica se dá por biópsia e estudo histopatológico. $O$ tratamento de escolha, por seus menores índices de recidiva, é a ressecção cirúrgica com margens amplas. A utilização de enxertos ou retalhos é frequentemente necessária para corrigir o defeito cutâneo deixado e permitir a cicatrização satisfatória.
\end{abstract}

Descritores: Doença de Bowen perianal; carcinoma epidermóide in situ; tratamento cirúrgico; retalho "V-Y".

\section{INTRODUÇÃO}

A Doença de Bowen (DB) foi descrita pela primeira vez em 1912 por John Templeton Bowen $(1857-1940)^{(1,2,3)}$. Porém só em 1939 foi relatada na região perianal ${ }^{(4)}$.

Trata-se de um distúrbio pré-canceroso (carcinoma in situ) que pode evoluir para o carcinoma epidermóide invasivo $^{(5)}$. Apresenta crescimento lento ${ }^{(6)}$, tendo como característica histopatológica principal a integridade da membrana basal da epiderme ${ }^{(7)}$.

$\mathrm{O}$ aspecto macroscópico da doença costuma ser variado, desde placas eritêmato-descamativas de contornos bem definidos até lesões vegetantes ${ }^{(6,8)}$. Pode haver hipo ou hiperpigmentação das lesões, e eventualmente exulceração ${ }^{(9)}$.

$\mathrm{Na}$ maioria das vezes a DB é assintomática ou apresenta mínimos sintomas ${ }^{(10)}$. Quando presentes, as principais queixas são queimação e prurido e, ocasionalmente, relata-se dor e sangramento ${ }^{(11,12)}$.

Dentre as patologias a serem consideradas no diagnóstico diferencial da DB devemos citar: Doença de Paget, carcinoma basocelular, ceratose seborréica, líquen simples crônico, líquen escleroatrófico, condiloma acuminado, melanoma, eczemas, extensão descendente de carcinoma de reto $^{(9)}$, psoríase $^{(11)}$ e papulose bowenóide ${ }^{(13)}$.

O tratamento de escolha da DB é a ressecção cirúrgica com margens de segurança ${ }^{(1,4,8,10,11,13)}$, muitas vezes sendo necessários enxertos ou avanços de retalhos para cobrir o defeito deixado na pele ${ }^{(3,4,13,14)}$. Porém diversas outras opções terapêuticas são ocasionalmente utilizadas no manejo da doença, tais como terapia fotodinâmica ${ }^{(2,9,10,13,14)}$, laser de argônio, crioterapia $^{(2,8,9,10,13)}$ e quimioterapia com 5-fluorouracil tópico com ou sem irradiação local ${ }^{(2,8,11,13)}$.

Trabalho realizado pelos médicos do Hospital Universitário Pedro Ernesto da UERJ.

Recebido em 15/01/2008

Aceito para publicação em 07/04/2008 
Relatar-se-á o caso clínico, conduta diagnóstica e terapêutica de uma paciente portadora de DB perianal avaliada e tratada pelos médicos autores deste artigo.

\section{RELATO DO CASO}

S. D., sexo feminino, 51 anos, branca, natural do Rio de Janeiro. História da doença iniciada há 2 anos com queimação e prurido perianal progressivamente mais intensos nos últimos 6 meses. Referia ainda sangramento anal ocasional. Sem alterações ao exame físico, exceto ao exame proctológico. À inspeção identificamos lesão eritêmato-escamosa, plana, de limites bem definidos, indolor, com aproximadamente $4 \mathrm{~cm}$ no maior diâmetro, acometendo região perianal anterior, com limites atingindo a margem anal e fúrcula vaginal posterior (Figura 1). Toque retal sem alterações, anuscopia evidenciou hemorroidas mistas, retossigmoidoscopia rígida normal até $18 \mathrm{~cm}$.

As hipóteses diagnósticas neste momento foram: Doença de Paget, DB e Psoríase. Realizada biópsia da lesão, para diagnóstico diferencial, cujo resultado histopatológico revelou queratinócitos atípicos em todos os níveis da epiderme: "Doença de Bowen X Papulose Bowenoide". Diante deste resultado foi indicado o tratamento cirúrgico para DB. O procedimento cirúrgico consistiu em ressecção da lesão com margens de segurança e correção do defeito cutâneo através da rotação de retalho "V - Y" com suprimento sanguíneo proveniente dos ramos perfurantes da artéria glútea (Figuras 2, 3 e 4). Paciente evoluiu sem intercorrências peri ou pós-operatórias. O laudo histopatológico da peça cirúrgica revelou "carcinoma de células escamosas in situ".

\section{DISCUSSÃO E CONCLUSÃO}

A DB foi descrita pela primeira vez por John Templeton Bowen em 1912. Até o momento não há mais de 200 casos relatados na literatura em todo o mundo $^{(2)}$. Trata-se de uma lesão pré-cancerosa, neoplasia intra-epitelial ou carcinoma in situ. Pode evoluir para o carcinoma epidermoide invasivo em aproximadamente 2-6\% dos $\operatorname{casos}^{(2,13)}$.

As alterações genéticas possivelmente encontradas e utilizadas como indicadores de uma maior tendência invasiva das dermatoses pré-malignas, (DB, Eritroplasia de Queyrat e Papulose Bowenóide) ${ }^{(5)}$ são as mutações no gene supressor tumoral p53, em até
$80 \%$ dos $\operatorname{casos}^{(13)}$ e a expressão do antígeno nuclear Ki-67. Ainda são necessárias mais pesquisas para definir o valor prognóstico da presença destas alterações quanto ao potencial de recorrência e invasão tumoral ${ }^{(10)}$.

É mais comum em áreas expostas ao sol: face, tronco e mãos, como a maioria dos tumores cutâneos. A ocorrência na região perianal é rara e, quando ocorre, geralmente acomete pacientes mais jovens de 3040 anos $^{(9)}$. É mais frequente em mulheres e indivíduos da raça branca ${ }^{(8)}$.

A ocorrência da DB em áreas não expostas ao sol pode estar associada a outras patologias como a infecção pelo HPV 16, 18, 34 ou 48, doenças inflamatórias intestinais e neoplasias de cólon ${ }^{(10)}$. Questionase a associação da DB com outras neoplasias malignas viscerais ${ }^{(5,8,13)}$.

Esta neoplasia apresenta crescimento lento e em muitos casos é oligo ou assintomática, justificando o retardo no diagnóstico ${ }^{(10)}$. Até mais de $40 \%$ dos casos podem ser encontrados durante estudo histopatológico de peças cirúrgicas de hemorroidectomia ${ }^{(11)}$.

Quando sintomática, as principais queixas referidas pelos pacientes com esta doença são o prurido, a queimação e algumas vezes sangramento ${ }^{(8,9,11)}$. Como no caso de nossa paciente em que a queixa básica era a queimação. $\mathrm{O}$ aspecto macroscópico da doença é variável desde lesões vegetantes até placas eritematosas, de contornos bem definidos, com presença de eczema, podendo existir áreas de fissuras ou exulcerações, e por vezes alterações da pigmentação, com hipo ou hiperpigmentação ${ }^{(9)}$.

O diagnóstico definitivo é fornecido pela biópsia da lesão mediante suspeita clínica após exame proctológico completo e cuidadosa inspeção perianal ${ }^{(8)}$.

Ao estudo histopatológico destas lesões podemos identificar numerosos achados, tendo todas estas alterações do epitélio como característica fundamental e marcante da doença o não acometimento da membrana basal de epiderme, caracterizando o carcinoma in situ. Entre elas podemos citar: hiperplasia da epiderme (papilomatose) e desorganização da mesma com perda da polaridade celular da camada basal para a córnea; hiperparaceratose; numerosas mitoses, algumas vezes atípicas; células displásicas com núcleos grandes, hipercromáticos, com halo não corado que as diferencia das células de Paget ${ }^{(1,5,13)}$. Já durante o estudo imuno-histoquímico pode-se encontrar o HPV em alta frequência ${ }^{(9)}$. Outras alterações que podem ser 


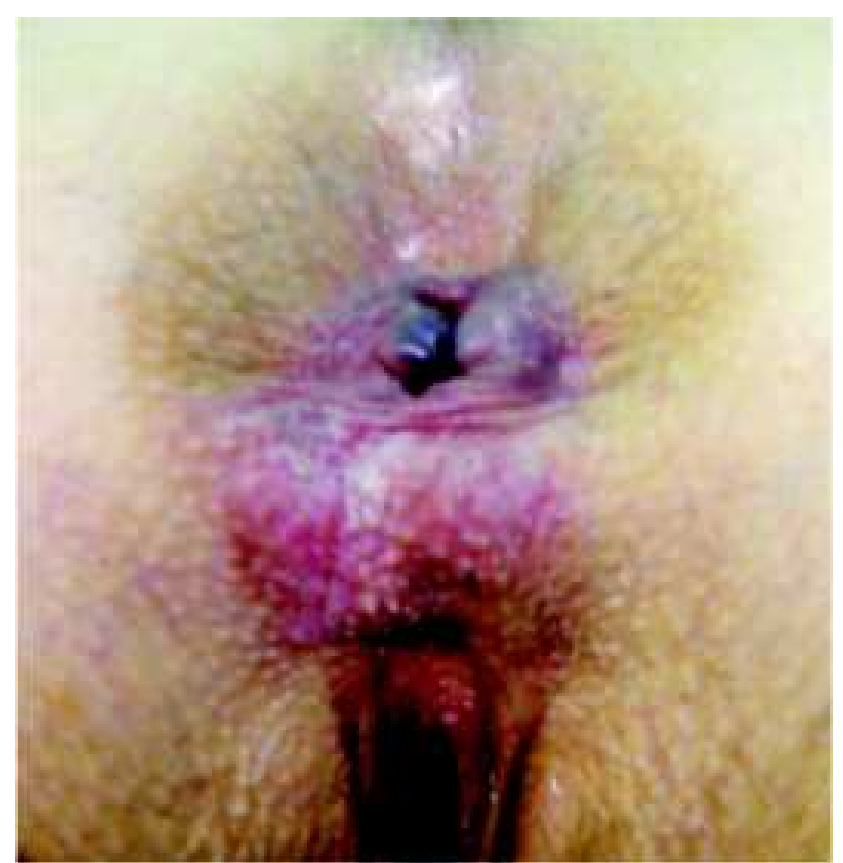

Figura 1 - lesão à inspeção anal.

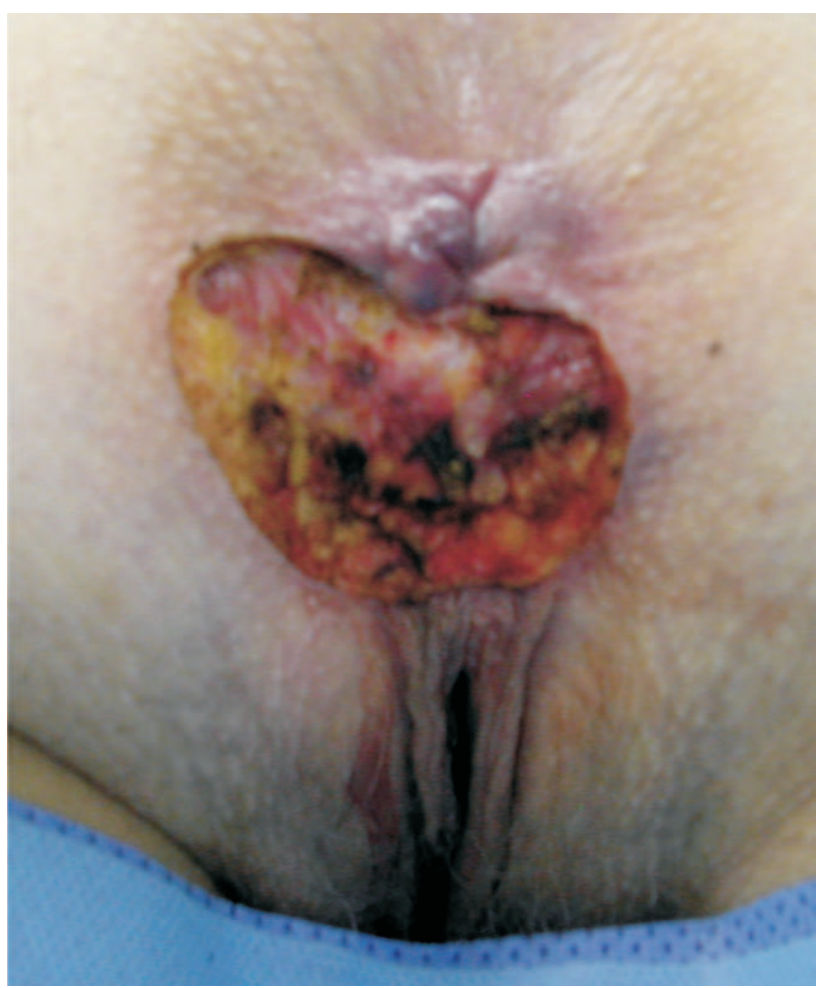

Figura 2 - defeito cutâneo após ressecção.

avaliadas por este estudo, no que diz respeito ao potencial invasor desta neoplasia pré-cancerosa, são a expressão do antígeno nuclear Ki-67 e a proteína produto do gene $\mathrm{p} 53^{(10)}$.

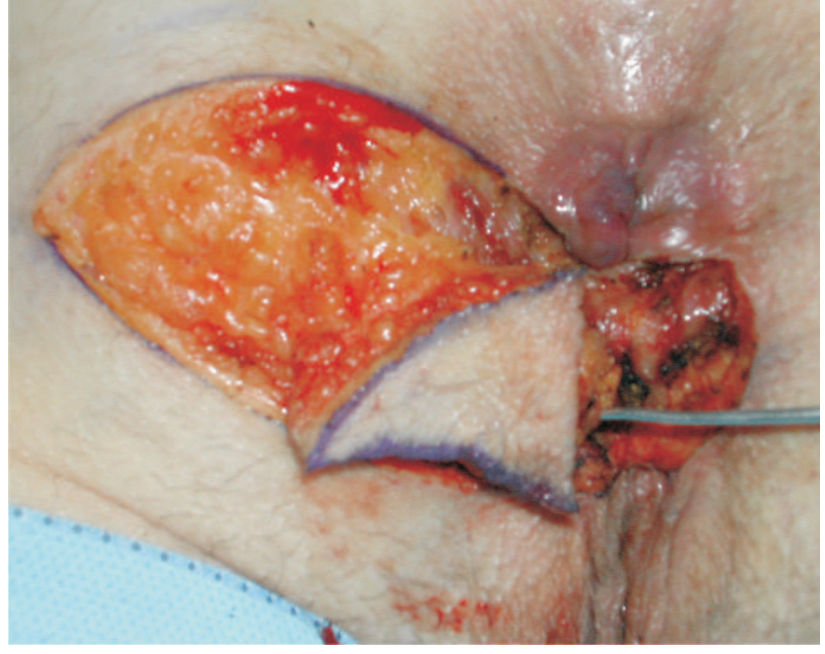

Figura 3 - rotação do retalho.

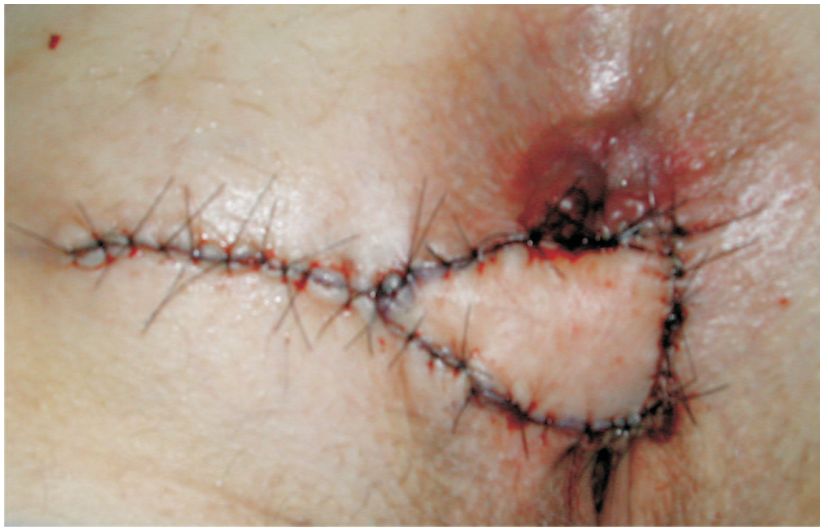

Figura 4-aspecto final do retalho cutâneo.

Diversas também são as patologias a serem lembradas durante a investigação diagnóstica numa suspeita de DB. Entre elas merecem ser citadas: psoríase, Doença de Paget, Papulose Bowenoide, eczemas, condiloma acuminado, eczemas, ceratose seborreica, líquen simples crônico, líquen escleroatrófico, melanoma, carcinoma basocelular, extensão descendente do carcinoma de reto.

No caso da Papulose Bowenoide cabe ainda ressaltar que histologicamente é indistinguível da DB. Os critérios clínicos serão então determinantes no diagnóstico diferencial destas duas entidades visto que a Papulose Bowenoide tende a ocorrer em pacientes mais jovens e cursar mais frequentemente com lesões múltiplas e pigmentadas. Porém, esta apresenta melhor prognóstico, pois raramente se transforma em carcinoma invasivo quando comparada à $\mathrm{DB}^{(5)}$.

Quanto às opções terapêuticas cada dia mais procura-se procedimentos menos invasivos, porém, a 
ressecção cirúrgica, permanece como consenso em toda literatura como primeiro tratamento de escolha. A criocirurgia (nitrogênio líquido) e a terapia fotodinâmica (substâncias fotossensibilizantes e radiação a laser) têm sido apontadas como opções terapêuticas com baixos índices de recidiva, e como uma possibilidade de retratamento mais simples nos casos de recorrência ${ }^{(9,}$ 14). Porém, em nossa opinião, e mesmo entre outros autores, nenhuma destas opções podem ser consideradas o melhor tratamento, permanecendo a exérese cirúrgica com margens amplas como o padrão ouro no manejo da DB.

Quanto ao tratamento cirúrgico preconiza-se a ressecção local alargada com margens iguais ou superiores a $1,0 \mathrm{~cm}^{(11)}$. Frequentemente os defeitos cutâneos deixados são grandes demais para permitir um fechamento primário ou por segunda intenção satisfatórios. Nestes casos podemos utilizar técnicas tais como, enxertos ou anoplastia com avanço de retalhos cutâneos, entre eles o "V-Y", "S" e "C", compostos de pele e tecido subcutâneo ${ }^{(13)}$.

Entre as técnicas de retalhos, a mais comumente utilizada, segundo relatos da literatura, é a "V-Y"(3,4). Esta foi a conduta escolhida por nós para o tratamento de nossa paciente. É também o procedimento utilizado como rotina pela Mayo Clinic ${ }^{(3)}$.

A exérese ampla da lesão é o tratamento que apresenta menores índices de recidiva, que variam na literatura entre 16 e $31 \%$. A sobrevida em 5 anos é de $83,3 \%{ }^{(8)}$.

No caso da DB não existe um protocolo bem definido, universalmente aceito, para o seguimento dos pacientes. Recomenda-se o acompanhamento por pelo menos 10 anos, com exame físico e anuscopia cada 3 a 6 meses, sigmoidoscopia anual e colonoscopia cada 2 a $5 \operatorname{anos}^{(8,13)}$.

Com o relato deste caso foi possível reafirmar o caráter oligo ou assintomático da DB, com queixas inespecíficas e aspecto macroscópico da lesão variável, permitindo uma diversidade de diagnósticos diferenciais. O início da história da doença geralmente é de longa data, com crescimento e evolução lentos, retardando assim o diagnóstico. Este deve ser feito através de biópsia e estudo histopatológico. Com a confirmação diagnóstica o tratamento deve ser imediatamente instituído. Pelos menores índices de recidiva opta-se pela ressecção com margens de segurança, procedimento cirúrgico que por muitas vezes exige o emprego de retalhos cutâneos para correção do defeito deixado.

ABSTRACT: The authors report a case and aimed at discussing about Bowen's disease, an unusual pathology, especially in perianal area. It is an in situ carcinoma with invasive potential. Epidermal's histological abnormalities with basal membrane preservation is its main characteristic. This disease presents a slow progression, few or no specific symptoms and variable macroscopic aspect. These facts lead in several times to a late diagnosis. Biopsies and histopathological study confirm the diagnosis. The treatment of choice is wide surgical resection. Often it is necessary to utilize grafts or flaps to correct the cutaneous defects and allows a satisfactory cicatrization.

Key words: Perianal Bowen's disease; in situ epidermoid carcinoma; surgical treatment; "V-Y” flap.

\section{REFERÊNCIAS}

1. Quilici FA, Reis Neto JA, editores. Atlas de Proctologia: do diagnóstico ao tratamento. São Paulo: Lemos Editorial; 2000.

2. Margenthaler JA, Dietz DW, Mutch MG, Birnbaum EH, Kodner IJ, Fleshman JW. Outcomes, Risk of Other Malignancies, and Need for Formal Mapping Procedures in Patients With Perianal Bowen's Disease. Dis Colon Rectum 2004; 47(10):1655-1661.

3. Hormaza JÁ, Martinez C, Mateus L, Rozo S, Escobar J, Torres MC, Serrano JM \& Castro JM. Enfermedad de Bowen perianal. Ver colomb Gastroenterol 2003; 18(2):107-111.

4. Sarmiento JM, Wolff BG, Burgart LJ, Frizelle FA, Ilstrup DM. Perianal Bowen's disease: Associated tumors, human
Papillomavirus, surgery, and other controversies. Dis Colon Rectum 1997; 40(8):912-18.

5. Cotran RS, Kumar V, Collins T. Robbins Patologia Estrutural e Funcional. $6^{a}$ ed. Rio de Janeiro: Editora Guanabara Koogan; 2000.

6. Townsend, C. M. Tratado de cirurgia: As bases biológicas da prática cirúrgica moderna. 16 ed. Rio de Janeiro: Editora Guanabara Koogan; 2003.

7. Brasileiro Filho G, Pittella JEH, Pereira FEL, Bambirra EA, Barbosa AJA. Bogliolo Patologia. $5^{\text {a }}$ ed. Rio de Janeiro: Editora Guanabara Koogan; 1994.

8. Jucá MJ, Gomes EG, Feijó MJF, Costa FAM. Doença de Bowen Perianal: Relato de caso. Rev bras Coloproct 2005; 25(4):378-381. 
9. Moraes AM, Leite SHR, Cintra ML, Terrazas ER, Souza EM. Doença de Bowen na região perianal tratada com criocirurgia com nitrogênio líquido. An bras Dermatol 2002; 77(5):571-576.

10. Marchesa P, Fazio V W, Oliart S, Goldblum JR \& Lavery IC. Perianal Bowen's disease: A clinicopatologic study of 47 patients. Dis Colon Rectum 1997; 40(11):1986-93.

11. Corman ML, Allison SI, Kuehne JP, editors. Handbook of Colon \& Rectal Surgery. Philadelphia: Lippincott Williams \& Wilkins; 2002.

12. Bertagni A, Vagliasindi A, Ascari RA, Valmori L \& Verdecchia GM. Perianal Bowen's disease: a case report and review of the literature. Tumori 2003; 89(4):16-28.

13. Cleary RK, Schaldenbrand JD, Fowler JJ, Schuler JM \& Lampman RM. Perianal Bowen's disease and anal intraepithelial neoplasia: review of the literature. Dis Colon Rectum 1999; 42(7):945-51.

14. Runfola MA, Weber TK, Rodriguez-Bigas MA, Dougherty TJ, Petrelli NJ. Photodynamic Therapy for Residual Neoplasms of the Perianal Skin. Dis Colon Rectum 2000; 43(4):499-502.

\section{Endereço para correspondência:}

LUCIANA PAES PEIXOTO NETTO

Av. Das Américas, 4319 - Bloco K1/103

Barra da Tijuca - Rio de Janeiro - RJ 22631-004

Fax: (21) 3325-3064

E-mail: lucippnetto@terra.com.br 